\title{
Chrysosporium queenslandicum: a potent keratinophilic fungus for keratinous waste degradation
}

\author{
Tarun Kumar Kumawat ${ }^{1} \cdot$ Anima Sharma $^{2} \cdot$ Seema Bhadauria $^{3}$
}

Received: 11 October 2016/Accepted: 10 April 2017/Published online: 20 April 2017

(c) The Author(s) 2017. This article is an open access publication

\begin{abstract}
Purpose Keratinous wastes are the solid environmental pollutant generated from poultry farms, slaughterhouses and barber's shops. The aim of the present study is the degradation of keratinous wastes in an eco-friendly way by biological methods, which should further be helpful to reduce the wastes and recycled into valuable feed and fertilizers.

Methods Degradation of keratinous substrates was assessed by highly potent keratinophilic fungi, namely Chrysosporium queenslandicum TKKASb Apinis and R.G. Rees. This chicken feather degrading fungal strain previously isolated and identified by morphological and $18 \mathrm{~s}$ rDNA sequencing in laboratory, was used in the present study. Ch. queenslandicum was inoculated into the basal salt medium (BSM) with keratinous substrates for 12 and 24 days at $28 \pm 2{ }^{\circ} \mathrm{C}$ to observe degradation. The rate of degradation was expressed as weight loss of keratin substrate over incubation days and $\mathrm{pH}$ variation.

Results In this study, Ch. queenslandicum showed maximum degradation on chicken feathers followed by human nail clippings, animal hair and human hair. The degradation rate on chicken feather was $38.40 \pm 0.80$ and $46.40 \pm 2.50 \%$ after 12 and 24 days, respectively. The basal salt medium's $\mathrm{pH}$ was increased over incubation
\end{abstract}

Anima Sharma

sharmaanima6@gmail.com

1 Department of Biotechnology, JECRC University, Jaipur, Rajasthan, India

2 ICAR-Central Sheep and Wool Research Institute, AridRegion Campus, Bikaner, Rajasthan, India

3 Department of Microbiology, JECRC University, Jaipur, Rajasthan, India time. Scanning electron microscopy (SEM) examination also demonstrated the degradation of chicken feathers. Conclusions The results suggest that Ch. queenslandicum possess the potential biotechnological applications which can be used in the hydrolysis of keratinous waste and recycling of poultry waste for environmental protection. The hydrolyzed keratinous material can also be utilized as the source of fertilizers for plants and feed for animals.

Keywords Chrysosporium queenslandicum - Keratinous wastes $\cdot$ Environmental pollutant $\cdot$ Degradation $\cdot$ Fertilizers

\section{Introduction}

Environmental wastes are originated in enormous amount from many countries and contain a considerable amount of protein and carbon compounds (Park and Son 2009). The keratinous wastes are considered as the environmental pollutants (Werlang and Brandelli 2005; Kumawat et al. 2016a). Food industry, poultry farm, slaughterhouse, leather industries and wool industries are constantly producing million tons of keratinous wastes. The major producers include USA, Brazil and China, account for more than 40 million tons per year (Sharma and Gupta 2016). According to a current report, India's part alone is 350 million tons (Agrahari and Wadhwa 2010; Sousa et al. 2015). The keratin-containing wastes are dumped, buried, used for land filling, or incinerated (Fellahi et al. 2016). These activities cause the soil, water and air pollution. Discarded feathers cause various human ailments, including chlorosis and fowl cholera (Williams et al. 1991).

Keratin protein is a tough, fibrous and the third most abundant polymer in the environment after cellulose and 
chitin (Lange et al. 2016). This protein provides an exoskeleton covering of animals in the form of horns, hooves, hair, and feathers (Gupta and Nayak 2015). The mammalian keratin proteins are categorized into two groups based on their structure and function: (a) hard keratin and (b) soft keratin (Kakkar et al. 2014). Due to the strength and stability of keratin protein, very few microorganisms are able to degrade it down. Keratinophilic fungi have the capability to decompose the keratinous wastes with the production of the keratinase enzyme (Sharma and Rajak 2003; Kumawat et al. 2013; Sharma et al. 2015a). Soils are the best place for the growth and incidence of keratinophilic fungi, because of the presence of organic materials and keratinous substrates (Ulfig 2006; Sharma et al. 2015b).

Keratin-rich by-products, i.e., chicken feathers, horns and hooves are the resource of nutrient for animals (amino acids) and plants (N, S) (Kornillowicz-Kowalska and Bohacz 2011). The preparation of compost fertilizers from the keratinous wastes was also abandoned in the European countries, and from biochemical point of view, the keratinous wastes which contain about $20-25 \%$ protein should represent superior source of nitrogen for plants (Gousterova et al. 2003).

Chrysosporium queenslandicum belongs to the family Onygenaceae and isolated first time from the feathers of domestic fowl Cunnumala, Southern Queensland, Australia (Apinis and Rees 1976). Antifungal compound "Queenslandon", and antibacterial compounds "chrysoqueen (1) and chrysolandol (2)" related to members of the dihydronaphthoquinone group was produced by Chrysosporium queenslandicum IFM 51121 (Hoshino et al. 2002; Ivanova et al. 2002).

The focus of this paper is to evaluate the keratinous waste decomposition by Chrysosporium queenslandicum. Reduction of keratinous wastes by Ch. queenslandicum showed the biodegrading potential as well as management of keratinous wastes. The degraded keratinous wastes can be used as the source of feed and fertilizers.

\section{Materials and methods}

\section{Fungal culture}

The fungal culture of Chrysosporium queenslandicum TKKASb ((GenBank accession number KU560575) was isolated from poultry farm house soil of Rajasthan by the hair baiting technique, was earlier confirmed by morphological and 18s rDNA sequencing (molecular characterization) in the laboratory (Kumawat et al. 2016b). The strain was maintained on Sabouraud's dextrose agar (SDA).

\section{Degradation of different keratinous waste substrates}

The degradation of keratinous substrates (chicken feathers, human hair, animal hair and human nail clippings) was assessed at different incubation period, i.e., 12 and 24 days by weight loss method (Singh 2003). The keratinous substrates degradation from Chrysosporium queenslandicum was tested in basal salt medium $\left(\mathrm{NaCl}, 0.5 ; \mathrm{MgCl}_{2} \cdot 6 \mathrm{H}_{2} \mathrm{O}, 0.1 ; \mathrm{CaCl}_{2}\right.$, $0.06 ; \mathrm{KH}_{2} \mathrm{PO}_{4}, 0.5$; and $\mathrm{K}_{2} \mathrm{HPO}_{4} 0.5$; keratinous substrates; distilled water, $1 \mathrm{~L}$; $\mathrm{pH}$ 7.0) (Sharma et al. 2012). Chrysosporium queenslandicum was inoculated into the flask containing $100 \mathrm{ml}$ of BSM with $250 \mathrm{mg}$ of keratinous substrates, and incubated at $28{ }^{\circ} \mathrm{C}$ on an orbital shaking incubator (Remi CIS-24 Plus) at $70 \mathrm{rpm}$ for 12 and 24 days. A control, having the keratin substrates without keratinophilic fungal suspension, was also run along with the test flasks. The degradation by Chrysosporium queenslandicum was expressed as percentage weight loss of keratinous waste substrates. The experiment was performed in triplicates.

\section{Determination of percentage of degradation}

After the incubations days, the keratinous substrates fragments were collected on preweighed Whatman filter paper No. 1 and dried at $40{ }^{\circ} \mathrm{C}$ for $48 \mathrm{~h}$ and weighed for final weight. The keratin degradation by each keratinophilic species was expressed as percentage weight loss. The percent of keratinous substrates degradation was determined by weight loss method and calculate percentage weight loss using the following equation (Kim et al. 2001): Percentage weight loss $(\%)=(\mathrm{IW}-\mathrm{FW}) \times 100 / \mathrm{IW}$ where IW is the initial weight, FW is the final weight.

\section{pH variation}

A clear-cut confirmation to assess the progress of keratinous substrates degradation was obtained by observing the changes in hydrogen ion concentration of the basal salt media. Changes in the $\mathrm{pH}$ of the BSM after incubation time were also determined using digital pH meter (Model 181, Electronics India).

\section{Scanning electron microscopy (SEM)}

To characterize the degradation pattern of the chicken feather degradation by Chrysosporium queenslandicum at microscopic level, scanning electron microscopy (SEM) was used. For examination of a degraded chicken feathers under a scanning electron microscope, the degraded chicken feather sample from basal salt medium (after incubation days) was first washed using distilled water, then treated with acetone for dehydrating followed by air- 
drying. The dried samples were then mounted over the stubs with double-sided carbon tape. A thin layer of gold was coated over the samples using an automated sputter coater QUARUM-Q15OAS (Quorum Technologies, UK). The specimens and preparations were observed using a scanning electron microscope EVO-18 SEM (Carl Zeiss, Germany) at an accelerating voltage of $20 \mathrm{kV}$ (Mehta et al. 2014).

\section{Statistical analysis of data}

Results are given as mean \pm Standard error (SE) of $n$ observations taken in three replicates $(n=3)$. Data obtained were statistically analyzed with one-way analysis of variance (ANOVA) and the observations were considered significant when $P$ value was less than $0.05(P<0.05)$.

\section{Results}

The degradation of various keratinous waste substrates from Chrysosporium queenslandicum was accessed on the percent weight loss of substrates during treatment. The degradation percentage (\%) after 12 days of incubation revealed significant differences $(P<0.05)$. The percentage of degradation of chicken feathers, human hair, animal hair and human nail clippings treated was found to be $38.40 \pm 0.80, \quad 08.80 \pm 2.12, \quad 13.60 \pm 1.06 \quad$ and $22.40 \pm 1.44 \%$, respectively, after 12 days of incubation. The results of feather degradation of Chrysosporium queenslandicum were shown in figure 1. After 24 days incubation, the results of keratinous substrates degradation revealed significant differences $(P<0.05)$. The percentage weight loss of chicken feathers, human hair, animal hair and human nail clippings after 24 days incubation was $46.40 \pm 2.50, \quad 22.40 \pm 1.74, \quad 19.20 \pm 0.40 \quad$ and $30.80 \pm 1.20 \%$, respectively. It was very clear that keratinous waste substrates degradation was highest in sample subjected to long time incubation (Fig. 1).

In the present study, changes in $\mathrm{pH}$ of the culture medium due to the keratinous substrates degradation process were observed after 12 and 24 days of incubation. The $\mathrm{pH}$ of the control cultures did not change during the incubation periods. Keratinous substrates degradation was accompanied by alkalization of the culture medium with elevation of $\mathrm{pH}$ from 7.67 and 7.93 for human hair, 7.90 and 7.73 for animal hair, 7.95 and 8.00 for human nail clippings and 8.11 and 8.16 for chicken feathers, respectively, after 12th and 24th days of incubation (Fig. 2). Statistical analysis showed a significance difference $(P<0.05)$ among tested treatments. Such an alkalinisation of the medium may be due to excretion of excess nitrogen via deamination and ammonium excretion.

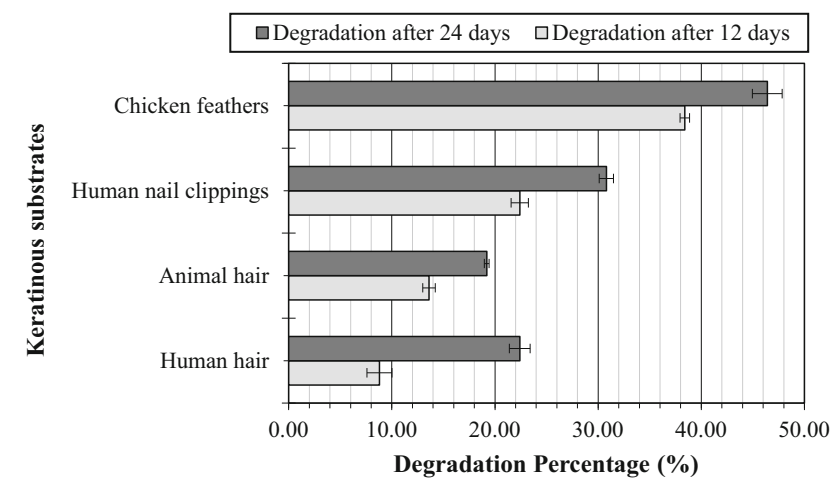

Fig. 1 Degradation percentage (\%) of keratinous substrates by Chrysosporium queenslandicum; data means and error bars at each point indicate \pm SE. Statistical analysis showed a significant difference $(P<0.05)$ among tested treatments

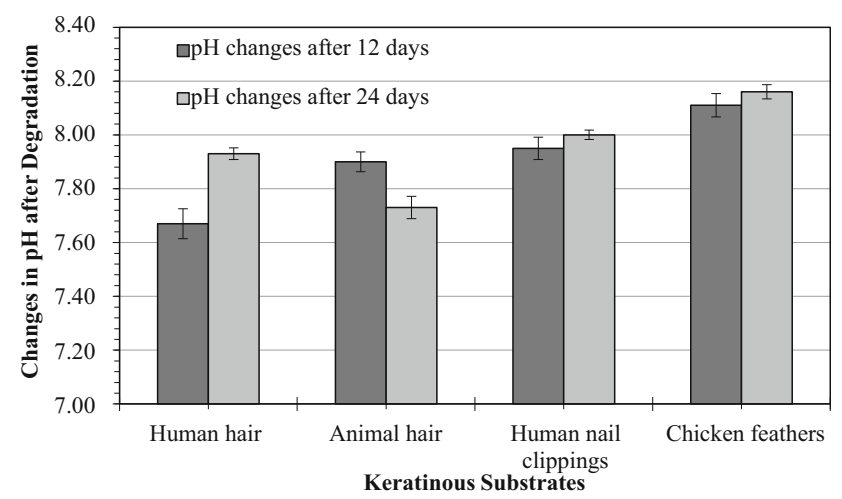

Fig. 2 Changes in $\mathrm{pH}$ of basal salt medium after keratin degradation by Chrysosporium queenslandicum; Data means and error bars at each point indicate \pm SE. Statistical analysis showed a significant difference $(P<0.05)$ among tested treatments

Keratinous substrates from control flasks showed no signs of degradation (Fig. 3a). In contrast, keratin substrates from experimental flasks showed varying degrees of digestion after incubation days (Fig. 3b). Scanning electron microscopy (SEM) was applied to visualize and confirm the degradation of chicken feather by Chrysosporium queenslandicum. Image of micrographs clearly shows the degradation of chicken feather shaft and barbs and shows the breakdown and weakening of the chicken feather structure by $\mathrm{Ch}$. queenslandicum, thus indicating keratinolysis (Fig. 4a). The shaft of feathers with barbs (Fig. 4b) could be clearly observed in SEM micrographs of uninoculated chicken feathers.

\section{Discussion}

Keratinophilic fungi are able to colonize different keratinous substrates and decompose them in low molecular weight (Maruthi et al. 2011). Several keratinophilic fungi 
Fig. 3 Degradation of chicken feathers; a control chicken feathers, b degraded chicken feathers by Chrysosporium queenslandicum
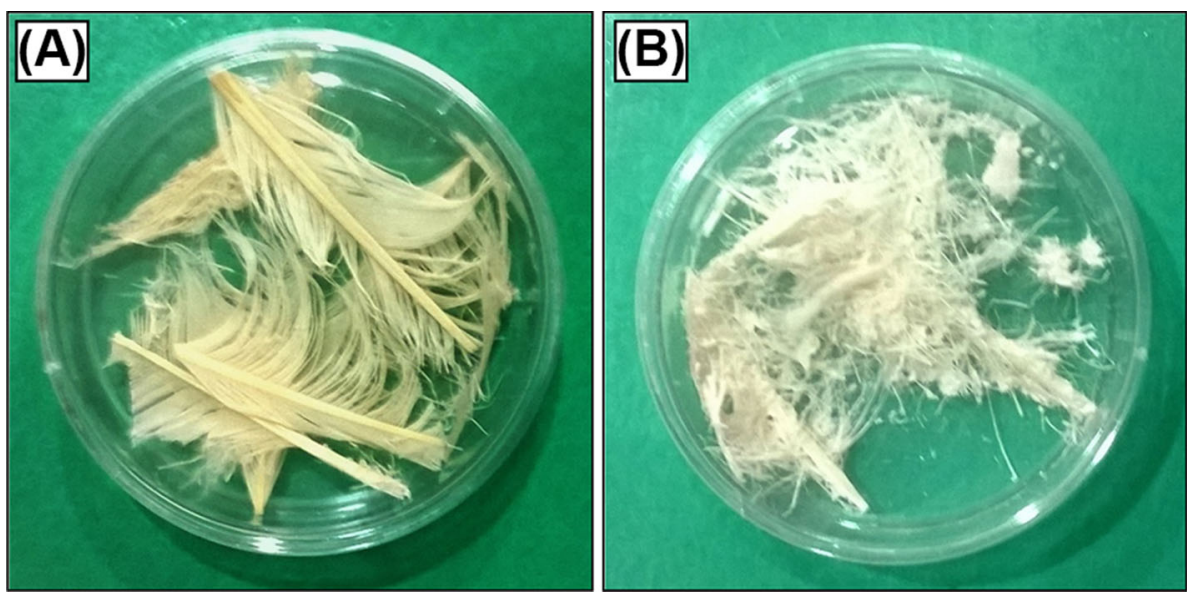

Fig. 4 Scanning electron microscopic (SEM) images of $\mathbf{a}$ undigested and $\mathbf{b}$ degraded chicken feathers by

Chrysosporium queenslandicum at $\times 704$
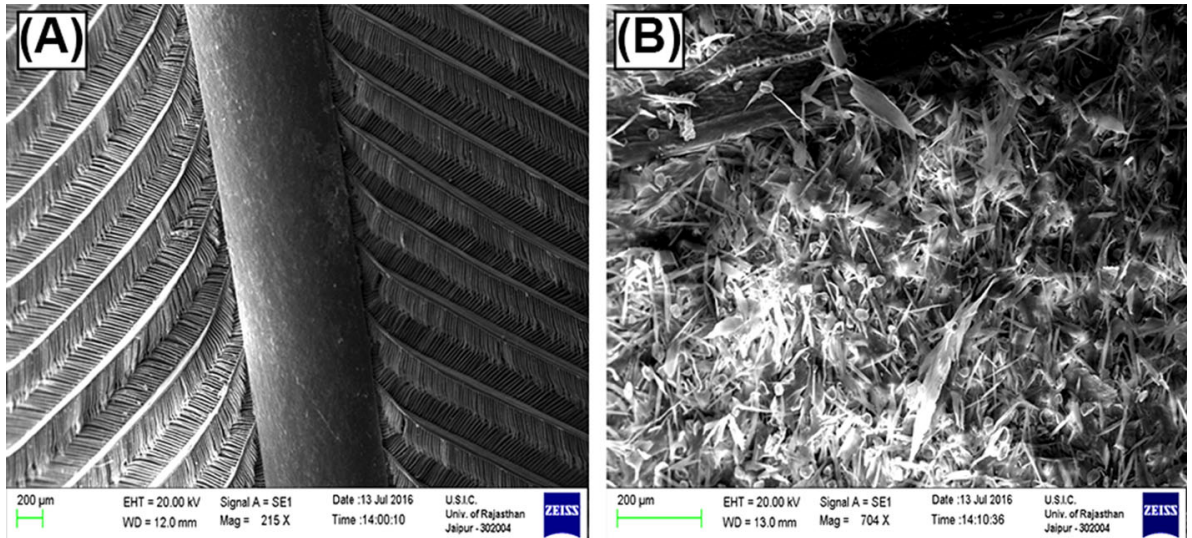

use keratinous substrates as source of carbon and nitrogen (Gopinath et al. 2015). Keratinous waste degradation in BSM with microbial cultures is one of the most capable techniques to utilize keratin protein and to obtain important by-products (Laba and Rodziewicz 2014). According to Syed et al. (2009), microbiological degradation of keratin waste is also an ecologically and economically safe method of utilization of such waste.

We have isolated and identified a potent keratinophilic fungus, Chrysosporium queenslandicum. This isolate showed the degradation of various keratinous substrates. The present study describes the degradation of various keratinous substrates in basal salt medium, changes of $\mathrm{pH}$ and scanning electron microscopy. In this study, $C h$. queenslandicum showed maximum degradation on chicken feathers followed by human nail clippings, animal hair and human hair after 12 days of incubation. After 24 days of incubation, $C h$. queenslandicum showed maximum degradation on chicken feathers followed by human nail clippings, human hair and animal hair. Muhsin and Hadi (2002) reported that chicken feather was highly degraded by Aspergillus flavus (32\%). Kumawat et al. (2016a) observed that the keratinous waste degradation was the highest on the chicken feathers (39.2\%) and the $\mathrm{pH}$ increased from the initial $7.0-8.15$ by colonization of Arthroderma multifidum.

In the present study, percentage of degradation of human hair was found to be $08.80 \pm 2.12$ and $22.40 \pm 1.74 \%$, after 12 and 24 days, respectively. Muhsin and Hadi (2002) observed the rate of degradation in which human hair had the highest degradation rate Chrysosporium pannicola $62 \%$ and Microsporum gypseum $48 \%$. Deshmukh and Verekar (2014) studied that all isolated 13 species viz. Aphanoascus durus, Arthroderma corniculatum, Auxarthron umbrinum, Chrysosporium evolceanui, Chrysosporium indicum, Chrysosporium tropicum, Chrysosporium zonatum, Chrysosporium states of Arthroderma tuberculatum, Chrysosporium state of Ctenomyces serratus, Gymnascella dankaliensis, Microsporum gypseum, Myriodontium keratinophilum and Trichophyton mentagrophytes were decomposed human hair (18.4-40.2\%) after four weeks of incubation.

The degradation percentage for the human nail clippings was $22.40 \pm 1.44$ and $30.80 \pm 1.20 \%$ after 12 and 24 days incubation, respectively. Oyeka and Gugnani (1998) reported that Scytalidium hyalinum degraded $40 \%$, whereas 
Scytalidium japonicum degraded $38 \%$ of human nail clippings. In the similar research, in another case Fusarium solani degraded the human nail clippings (43\%). Sharma et al. (2011) studied that Microsporum gypseum (49.34\%) and Trichophyton verrucosum $(49.34 \%)$ showed the greatest degradation of animal hair. These keratin substrates exhibited low degradation by Fusarium oxysporum (16.66\%). Bohacz (2017) reported the ability of strains of Aphanoascus fulvescens and Chrysosporium articulatum isolated from soil (phaesol) to degrade native feather keratin. According to them, keratinophilic fungi exhibit the keratinolytic activity against native feather keratin.

In this study, the changes in $\mathrm{pH}$ were assessed after the degradation of keratinous wastes by $C h$. queenslandicum. The $\mathrm{pH}$ of the medium-containing keratinous substrates was increased after 12 and 24 days incubation in the experimental flask. Kaul and Sumbali (1999) stated that alkalinisation of the medium may be due to excretion of excess nitrogen via deamination and ammonium excretion. Godheja and Shekhar (2014) reported that there was a gradual increase of $\mathrm{pH}$ in to the alkaline phase for feathers till 25 day incubation during the process of biodegradation.

Scanning electron microscopy (SEM) was employed to examine structural changes during the chicken feather degradation. Koutb et al. (2012) reported that the chicken feathers were completely degraded after 7 days of incubation by Aspergillus niger. Mehta et al. (2014) studied the scanning electron microscopy of chicken feather degradation after seven days by Bacillus sonorensis at $8000 \times$ magnification. Kshetri and Ningthoujam (2016) reported the degradation of chicken and other bird feathers by Bacillus sp. MBRL 575. Degradation of feather barbules was apparent from $12 \mathrm{~h}$ of incubation onwards and the complete degradation ( $98 \%$ weight loss) was observed after $48 \mathrm{~h}$ at $30{ }^{\circ} \mathrm{C}$. Scanning electron micrograph of degraded chicken feather by Bacillus sp. MBRL 575 after 12 and $24 \mathrm{~h}$ of incubation were observed by scanning electron microscope.

\section{Conclusion}

The keratinophilic fungus isolate, Chrysosporium queenslandicum, degraded the various keratinous wastes (chicken feathers, hairs) effectively and showed the keratinolytic activity. The keratinous waste degradation by $C h$. queenslandicum is not only economical but also a possible process for better management of keratinous wastes. The isolate could be used for biotechnological application in recycling of poultry waste for environmental protection (production of nitrogenous fertilizer and animal feed) and its fermentation broth could be useful in leather industry and textile industry, etc.
Acknowledgement We thank to Director, School of Sciences for encouragement and Head, Department of Biotechnology, JECRC University, Jaipur and Department of Medical Microbiology, PGIMER, Chandigarh (India) for providing the opportunity and facilities to complete the work.

\section{Compliance with ethical standards}

Conflict of interest The authors have no conflict of interest to declare.

Open Access This article is distributed under the terms of the Creative Commons Attribution 4.0 International License (http://crea tivecommons.org/licenses/by/4.0/), which permits unrestricted use, distribution, and reproduction in any medium, provided you give appropriate credit to the original author(s) and the source, provide a link to the Creative Commons license, and indicate if changes were made.

\section{References}

Agrahari S, Wadhwa N (2010) Degradation of chicken feather a poultry waste product by keratinolytic bacteria isolated from dumping site at Ghazipur poultry processing plant. Int J Poult Sci 9:482-489. doi:10.3923/ijps.2010.482.489

Apinis AE, Rees RG (1976) An undescribed keratinophilic fungus from southern Queensland. Trans Br Mycol Soc 67:522-524. doi:10.1016/S0007-1536(76)80188-X

Bohacz J (2017) Biodegradation of feather waste keratin by a keratinolytic soil fungus of the genus Chrysosporium and statistical optimization of feather mass loss. World J Microbiol Biotechnol 33:13. doi:10.1007/s11274-016-2177-2

Deshmukh SK, Verekar SA (2014) Isolation of keratinophilic fungi from selected soils of Sanjay Gandhi National Park, Mumbai (India). J Mycol Med 24:319-327. doi:10.1016/j.mycmed.2014. 08.004

Fellahi S, Chibani A, Feuk-Lagerstedt E, Taherzadeh MJ (2016) Identification of two new keratinolytic proteases from a Bacillus pumilus strain using protein analysis and gene sequencing. AMB Express 6:42. doi:10.1186/s13568-016-0213-0

Godheja J, Shekhar SK (2014) Biodegradation of keratin from chicken feathers by fungal species as a means of sustainable development. J Bioremed Biodeg 5:232. doi:10.4172/2155-6199. 1000232

Gopinath SCB, Anbu P, Lakshmipriya T et al (2015) Biotechnological aspects and perspective of microbial keratinase production. Biomed Res Int 2015:140726. doi:10.1155/2015/140726

Gousterova M, Nustorova I, Goshev P, Christov D, Braikova K, Tishinov T Haertle, Nedkov P (2003) Alkaline hydrolysate of waste sheep wool aimed as fertilizer. Biotechnol Biotechnol Equip 17:140-145. doi:10.1080/13102818.2003.10817072

Gupta P, Nayak KK (2015) Characteristics of protein-based biopolymer and its application. Polym Eng Sci 55:485-498. doi:10. 1002/pen.23928

Hoshino Y, Ivanova VB, Yazawa K, Ando A, Mikami Y, Zaki SM, Karam AZ, Youssef YA, Grafe U (2002) Queenslandon, a new antifungal compound produced by Chrysosporium queenslandicum: production, isolation and structure elucidation. J Antibiot (Tokyo) 55:516-519. doi:10.7164/antibiotics.55.516

Ivanova VB, Hoshino Y, Yazawa K, Ando A, Mikami Y, Zaki SM, Grafe U (2002) Isolation and structure elucidation of two new antibacterial compounds produced by Chrysosporium queenslandicum. J Antibiot (Tokyo) 55:914-918. doi:10.7164/antibio tics.55.914 
Kakkar P, Madhan B, Shanmugam G (2014) Extraction and characterization of keratin from bovine hoof: a potential material for biomedical applications. Springerplus 3:596. doi:10.1186/ 2193-1801-3-596

Kaul S, Sumbali G (1999) Production of extracellular keratinase by keratinophilic fungal species inhabiting feathers of living poultry birds (Gallus domesticus): a comparison. Mycopathologia 146:19-24. doi:10.1023/A:1007086720237

Kim JM, Lim WJ, Suh HJ (2001) Feather-degrading Bacillus species from poultry waste. Process Biochem 37:287-291. doi:10.1016/ S0032-9592(01)00206-0

Kornillowicz-Kowalska T, Bohacz J (2011) Biodegradation of keratin waste: theory and practical aspects. Waste Manag 31:1689-1701. doi:10.1016/j.wasman.2011.03.024

Koutb M, Morsy FM, Bagy MMK, Hassan EA (2012) Optimization of extracellular keratinase production by Aspergillus Terreus isolated from chicken's litter. J Adv Lab Res Biol 3:210-216

Kshetri P, Ningthoujam DS (2016) Keratinolytic activities of alkaliphilic Bacillus sp. MBRL 575 from a novel habitat, limestone deposit site in Manipur, India. Springerplus 5:595. doi:10.1186/s40064-016-2239-9

Kumawat TK, Sharma V, Seth R, Sharma A (2013) Diversity of keratin degrading fungal flora in industrial area of Jaipur and keratinolytic potential of Trichophyton mentagrophytes and Microsporum canis. IJBBR 4:359-364

Kumawat TK, Sharma A, Bhadauria S (2016a) Biodegradation of keratinous waste substrates by Arthroderma multifidum. Asian J Appl Sci 9:106-112. doi:10.3923/ajaps.2016.106.112

Kumawat TK, Sharma A, Bhadauria S (2016b) Effect of culture media and environmental conditions on mycelium growth and sporulation of Chrysosporium queenslandicum. Int J ChemTech Res 9:271-277

Laba W, Rodziewicz A (2014) Biodegradation of hard keratins by two bacillus strains. Jundishapur J Microbiol 7:e8896. doi:10. 5812/jjm.8896

Lange L, Huang Y, Busk PK (2016) Microbial decomposition of keratin in nature-a new hypothesis of industrial relevance. Appl Microbiol Biotechnol 100:2083-2096. doi:10.1007/s00253-015$7262-1$

Maruthi YA, Lakshmi KA Rao SR, Chaitanya DA (2011) Chrysosporium tropicum - a potential feather/hair waste degrading keratinophilic fungi. E3 J Environ Res Manag 2:014-018

Mehta RS, Jholapara RJ, Sawant CS (2014) Isolation of a novel feather-degrading bacterium and optimization of its cultural conditions for enzyme production. Int J Pharm Pharm Sci 6:194-201

Muhsin TM, Hadi RB (2002) Degradation of keratin substrates by fungi isolated from sewage sludge. Mycopathologia 154:185-189. doi:10.1023/A:1016335623534
Oyeka CA, Gugnani HC (1998) Keratin degradation by Scytalidium species and Fusarium solani. Mycoses 41:73-76. doi:10.1111/j. 1439-0507.1998.tb00381.x

Park GT, Son HJ (2009) Keratinolytic activity of Bacillus megaterium F7-1, a feather-degrading mesophilic bacterium. Microbiol Res 164:478-485. doi:10.1016/j.micres.2007.02.004

Sharma S, Gupta A (2016) Sustainable management of keratin waste biomass: applications and future perspectives. Braz Arch Biol Technol 59:e16150684. doi:10.1590/1678-4324-2016150684

Sharma R, Rajak RC (2003) Keratinophilic fungi: nature's keratin degrading machines! Their isolation, identification and ecological role. Reson 8:28-40. doi:10.1007/BF02837919

Sharma M, Sharma M, Rao VM (2011) In vitro biodegradation of keratin by dermatophytes and some soil keratinophiles. Afr J Biochem 5:1-6

Sharma A, Chandra S, Sharma M (2012) Difference in keratinase activity of dermatophytes at different environmental conditions is an attribute of adaptation to parasitism. Mycoses 55:410-415. doi:10.1111/j.1439-0507.2011.02133.x

Sharma V, Kumawat TK, Sharma A, Seth R, Chandra S (2015a) Distribution and prevalence of dermatophytes in semi-arid region of India. Adv Microbiol 5:93-106. doi:10.4236/aim. 2015.52010

Sharma V, Kumawat TK, Sharma A, Seth R, Chandra S (2015b) Dermatophytes: diagnosis of dermatophytosis and its treatment. Afr J Microbiol 9:1286-1293. doi:10.5897/AJMR2015.7374

Singh CJ (2003) Optimization of an extracellular protease of Chrysosporium keratinophilum and its potential in bioremediation of keratinic wastes. Mycopathologia 156:151-156. doi:10. 1023/A:1023395409746

Sousa M, Souza O, Maciel M, Cruz R, Rego MG, Magalhaes O, Pessoa-Junior A, Porto A, Souza-Motta C (2015) Keratinolytic potential of fungi isolated from soil preserved at the Micoteca URM. Eur J Biotechnol Biosci 3:10-15

Syed DG, Lee JC, Li WJ, Kim CJ, Agasar D (2009) Production, characterization and application of keratinase from Streptomyces gulbargensis. Bioresour Technol 100:1868-1871. doi:10.1016/j. biortech.2008.09.047

Ulfig K (2006) Sludge liming decreases the growth of keratinolytic and keratinophilic fungi. Polish J Environ Stud 15:341-346

Werlang PO, Brandelli A (2005) Characterization of a novel feather degrading Bacillus sp. strain. Appl Biochem Biotechnol 120:71-79. doi:10.1385/ABAB:120:1:71

Williams CM, Lee CG, Garlich JD, Shih JCH (1991) Evolution of bacterial feather fermentation product, feather lyaste, as a feed protein. Poult Sci 70:85-94. doi:10.3382/ps.0700085 